\title{
Bilateral Inferior Petrosal Sinus Sampling by Unilateral Femoral Venous Approach
}

\author{
Jee Won Park, MD, Soonchan Park, MD, Jong Lim Kim, MD, Ha Young Lee, MD, \\ Ji Eun Shin, MD, Dong Ho Hyun, MD, Seung Won Jang, MD, Dae Chul Suh, MD
}

Purpose: Bilateral inferior petrosal sinus sampling (IPSS) is a direct method of distinguishing between pituitary and ectopic ACTH secretion. We present unilateral femoral route technique avoiding bilateral femoral venous puncture using two 4F catheters into both sides of IPSS in these obese patients.

Materials and Methods: Unilateral femoral puncture using $9 \mathrm{~F}$ guiding catheter allowed two 4F catheters which can be introduced in each side of inferior petrosal sinus. To reduce bleeding in the gap between 2 catheters at the diaphragm of the $9 \mathrm{~F}$ femoral sheath, we introduced a short guidewire provided along with femoral sheath. After removing the $9 \mathrm{~F}$ sheath after procedure, we applied manual compression as usual. We evaluated any technical difficulty and other complications including the presence of hematoma at the puncture site 1 day and 30 days later.

Results: Bilateral IPSS by using two 4F catheters in both inferior petrosal sinuses was possible via unilateral femoral route via $9 \mathrm{~F}$ sheath. There was no technical difficulty introducing $4 \mathrm{~F}$ catheters into each IPS of both sides. After removing $9 \mathrm{~F}$ femoral sheath, there was no other complication and no hematoma at the puncture site at 1 day and 30 days later.

Conclusion: Unilateral femoral venous approach with a 9-French sheath can be used in IPSS. This technique allowed to pass two 4F catheters for IPSS at both sides and could avoid unnecessary bilateral femoral puncture in these obese patients without any hematoma formation after the procedure.

Key Words : Inferior petrosal sinus sampling; Petrosal sinus sampling; Cushing's; Ectopic; Pituitary; Adrenocorticotropic hormone

\footnotetext{
All authors: Department of Radiology and Research Institute of Radiology, Asan Medical Center, Seoul, Korea

Received May 4, 2010; accepted after revision July 13, 2010.

Correspondence to: Dae Chul Suh, MD, Department of Radiology, University of Ulsan, College of Medicine, Asan Medical Center, 86 Asanbyeongwon-gil, Songpa-gu, Seoul 138-736, Korea.

Tel. 82-2-3010-4366 Fax. 82-2-476-0090 E-mail: dcsuh@amc.seoul.kr

Neurointervention $2011 ; 6: 23-26$

This is an Open Access article distributed under the terms of the Creative Commons Attribution Non-Commercial License (http://creativecommons.org/licenses/by-nc/3.0) which permits unrestricted non-commercial use, distribution, and reproduction in any medium, provided the original work is properly cited.
} 
Inferior petrosal sinus sampling (IPSS) is used for the evaluation of patients with Cushing's disease and the ectopic adrenocorticotropic hormone (ACTH) syndrome. This is an interventional procedure in which ACTH levels obtained from venous drainage very near the pituitary gland are compared to peripheral blood levels before and after corticotropin hormone $(\mathrm{CRH})$ stimulation. A gradient between these two locations indicates pituitary Cushing's disease, whereas the absence of a gradient suggests ectopic Cushing's disease (1). The high diagnostic accuracy of IPSS has led to consider it feasible and standard confirmatory test $(2,3)$.

This procedure requires selective catheterization of both inferior petrosal sinuses and bilateral femoral venous puncture as presently carried out is technically demanding in time and materials. Patients with Cushing's syndrome frequently have massive central obesity and bone landmark or femoral pulses may be difficult to palpate (4), which delay procedure by making difficult to proceed with blood sampling in time. For this reason, we present a simplified bilateral IPSS to make it easier by unilateral femoral venous approach.

\section{MATERIALS AND METHODS}

We evaluated the procedures in the three consecutive patients with IPSS who were suspicious for Cushing's syndrome. The first patient was a 39-year-old female with moon face, galactorrhea and irregular menstruation. She was $167 \mathrm{~cm}$ in height and $83 \mathrm{~kg}$ in weight.
She had hypercortisolism with increased 24 hours urinary free cortisol excretion as $117 \mu \mathrm{g} /$ day (reference range 20-90 $\mu \mathrm{g} /$ day) and plasma ACTH level was high as $84 \mathrm{pg} / \mathrm{ml}$ (reference range $<60 \mathrm{pg} / \mathrm{ml}$ ). She underwent magnetic resonance (MR) imaging of the pituitary fossa which revealed two distinct cystic mass on both sides of the pituitary. These findings suggested ACTH-dependent Cushing's syndrome and she was referred for IPSS.

The second patient was a 22-year-old male with weight gain and reddish striae on his abdomen. He was $177 \mathrm{~cm}$ in height and $99 \mathrm{~kg}$ in weight. His 24 hour urinary free cortisol was $107 \mu \mathrm{g} /$ day which was slightly above threshold and plasma ACTH level was 49.5 $\mathrm{pg} / \mathrm{ml}$. His MR revealed no discrete lesion in the pituitary gland. He underwent low dose dexamethasone suppression test to rule out Cushing's syndrome and IPSS to reveal its etiology.

The third patient was a 41-year-old male with moon face, hirsuitism and high blood pressure. He was 157 $\mathrm{cm}$ in height and $73 \mathrm{~kg}$ in weight. He had hypercortisolism with increased 24 hours urinary free cortisol as high as $1577 \mu \mathrm{g} /$ day and plasma ACTH level was 88 $\mathrm{pg} / \mathrm{ml}$. MRI revealed a $7 \mathrm{~mm}$ sized mass in the left side of the pituitary gland. He was referred for IPSS with suspected of Cushing's disease.

\section{Technique}

1. The patient was placed supine on the angiography suite table, and the bilateral groin was prepped and draped in sterile fashion.

2. The skin and subcutaneous tissue over the puncture

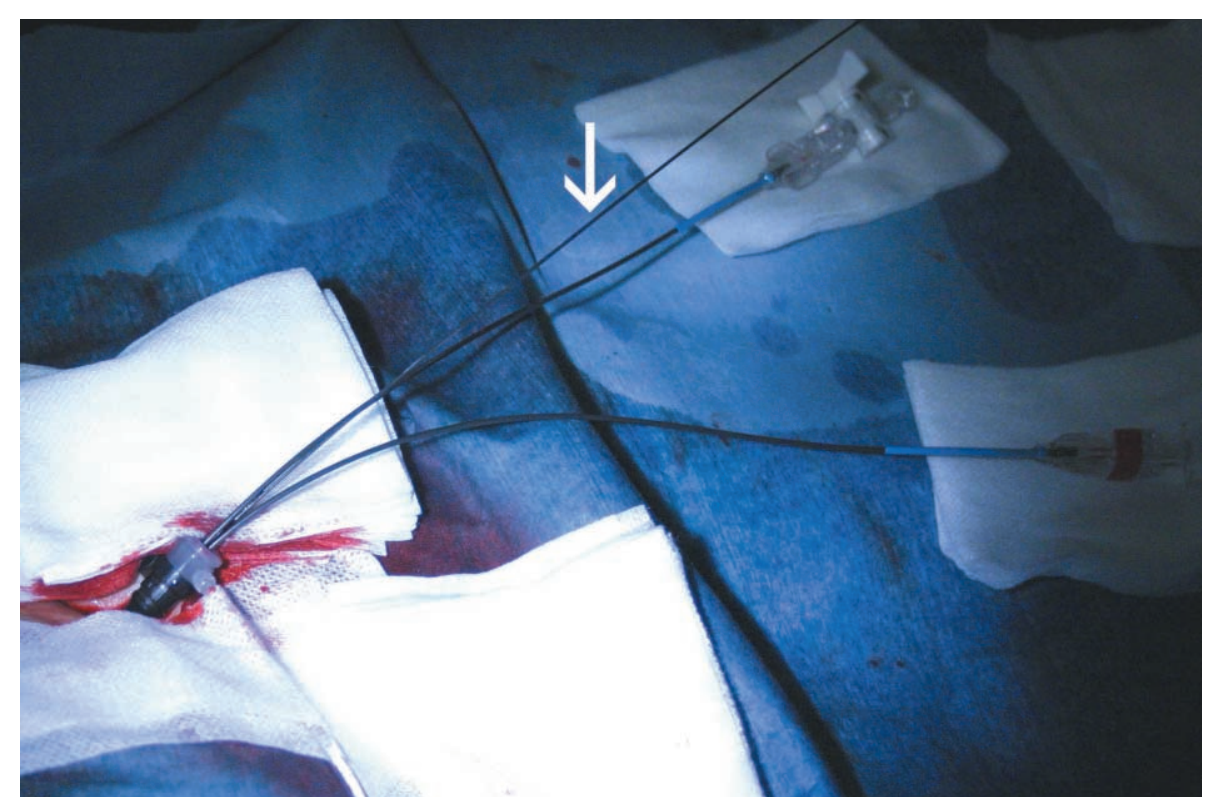

Fig. 1. Two 4F catheters were introduced via a $9 \mathrm{~F}$ femoral sheath. Note a short guidewire (arrow) to reduce bleeding in between two catheters at the diaphram of femoral sheath. 
site were infiltrated with local anesthesia in the right side first.

3. The Seldinger technique was used to place 9F sheaths into unilateral common femoral veins.

4. Through 9F sheath, two angled Davis 4F catheters were advanced over a Terrumo guide wire with fluoroscopic guidance.

5. A short guide wire used for puncture was inserted to the orifice of the sheath upside-down to prevent excessive bleeding.

6. Among two catheters, one catheter was advanced into the right internal jugular vein (IJV) and the other was placed in the left IJV.

7. At the $\mathrm{C} 1-2$ level, the catheters and wires are carefully directed medially and anteriorly to access the IPS. Once an IPS is catheterized, gentle and smooth venographic runs can opacify the ipsilateral IPS, superior petrosal sinus, cavernous sinus, and contralateral IPS. Roadmap guidance can help guide placement of the contralateral wire and catheter.

8. After the correct placement of catheters, simultaneous blood samplings of $3 \mathrm{cc}$ were obtained from each of the three ports (peripheral, left IPS and right IPS). After obtaining basal samples 0 and 5 minute, $\mathrm{CRH}$ at a dose of $1 \mu \mathrm{g} / \mathrm{kg}$ was administered and further peripheral and petrosal samples were drawn after 1, 3, 5 and 10 minute. Before each sample is drawn, the catheters are aspirated, and saline-diluted blood is discarded.

9. After blood sampling, catheters and sheath were removed and compression of the groin was done with pressure until venous hemostasis.

The ratios are calculated at baseline and at each time point after CRH injection between the each IPS and periphery. We considered positive result as a ratio of the higher of the two petrosal sinus plasma ACTH levels to that of the peripheral venous plasma ACTH of 2.0 or more before $\mathrm{CRH}$ administration and 3.0 or more after $\mathrm{CRH}$ administration. This is considered as being consistent with pituitary-dependent hypercortisolism.

\section{RESULTS}

Bilateral IPSS was successfully performed in all cases at the right side and there was no technical difficulty introducing 4F catheters into each IPS through 9F sheath. The mean time of procedure was 35 minutes (range 24-46 minutes) from puncture to catheterization of bilateral IPS.

The first patient was diagnosed as pituitarydependent hypercortisolism as a result of positive bilateral IPSS and underwent transsphenoidal pituitary adenoidectomy. Histological examination confirmed a corticotropic adenoma. Bilateral IPSS of the second patient showed the positive result but she was considered as pseudo-Cushing's syndrome based on low dose dexamethasone suppression test. It was considered false positive bilateral IPSS result and she was recommended to be followed through outpatient clinic. Bilateral IPSS of the third patient showed the negative result, but with positive MRI finding and biochemical results, he was referred for transsphenoidal surgery.

After removing 9F femoral sheath, there was no hematoma at the puncture site at 1 day and 30 days later. There were no other complications and all patients' tolerance was good.

\section{DISCUSSION}

Bilateral IPSS is a well established method for differential diagnosis of Cushing's disease. In 1977, IPSS was initially introduced in unilateral form by Corrigan and colleagues (5) as a means of identifying the pituitary as the central cause of hypercortisolism. However, it was later established that ACTH levels in venous drainage from the pituitary may be asymmetric, either due to corticotroph adenoma location or anatomical variation. Thus, simultaneous measurements from both IPS are necessary to avoid a falsely negative evaluation in the setting of a pituitary corticotroph adenoma (1). Bilateral IPSS was described by Doppman and colleagues (6) in 1984 emphasizing the importance of bilateral simultaneous sampling, but in which there is no precise description of femoral vein puncture. After that many reports of simultaneous bilateral IPSS using bilateral femoral venous approach has been published $(1-4,7)$. But patients with suspicious for Cushing's syndrome have massive central obesity as one of the most common sign, which makes difficult to find the location of femoral vein even with fluoroscopy as well as with palpation. Both common femoral veins eventually join to form inferior vena cava via common iliac vein, therefore there is no need to puncture bilateral common femoral vein.

Padayatty et al. (8) described bilateral sequential IPSS with unilateral femoral venous approach. In this study, catheter was withdrawn into the superior vena cava after the right IPSS followed by the left IPSS. But with method, because CRH was administered through 


\section{Jee Won Park, et al.}

an antecubital vein cannula at the time of femoral puncture, a direct interpetrosal sinus ratio could not be calculated due to the time interval between collections of the two samples. Because peripheral blood sample should be taken each time of an IPSS, this method required many blood samples and more procedure time.

Our results show that unilateral femoral venous approach with 9F sheath made bilateral simultaneous IPSS simpler. There was no friction between two 4F catheters within the sheath or inferior vena cava. We use a short guide wire to prevent excessive bleeding through the gap between two $4 \mathrm{~F}$ catheters in a $9 \mathrm{~F}$ sheath which was enough to reduce bleeding and there was only small amount of leakage. It needs to keep short guide wire stable not to enter into the sheath. We labeled each catheter not to confusing laterality. Double lumen sheath could be developed for making this step more convenient.

In conclusion, usage of two $4 \mathrm{~F}$ catheters through unilateral $9 \mathrm{~F}$ femoral sheath is a relatively simple and fast technique for bilateral IPSS without causing any further complication.

\section{References}

1. Utz A, Biller BM. The role of bilateral inferior petrosal sinus sampling in the diagnosis of Cushing's syndrome. Arq Bras Endocrinol Metabol 2007;51:1329-1338

2. Wiggam MI, Heaney AP, McIlrath EM, McCance DR, Sheridan $\mathrm{B}$, Hadden DR, et al. Bilateral inferior petrosal sinus sampling in the differential diagnosis of adrenocorticotropin-dependent Cushing's syndrome: a comparison with other diagnostic tests. $J$ Clin Endocrinol Metab 2000;85:1525-1532

3. Tomycz ND, Horowitz MB. Inferior petrosal sinus sampling in the diagnosis of sellar neuropathology. Neurosurg Clin N Am 2009;20:361-367

4. Miller DL, Doppman JL. Petrosal sinus sampling: technique and rationale. Radiology 1991;178:37-47

5. Corrigan DF, Schaaf M, Whaley RA, Czerwinski CL, Earll JM. Selective venous sampling to differentiate ectopic ACTH secretion from pituitary Cushing's syndrome. N Engl J Med 1977;296:861-862

6. Doppman JL, Oldfield E, Krudy AG, Chrousos GP, Schulte HM, Schaaf M, et al. Petrosal sinus sampling for cushing syndrome: anatomical and technical considerations. Work in progress. Radiology 1984;150:99-103

7. Findling JW, Kehoe ME, Shaker JL, Raff H. Routine inferior petrosal sinus sampling in the differential diagnosis of adrenocorticotropin (ACTH)-dependent Cushing's syndrome: early recognition of the occult ectopic ACTH syndrome. J Clin Endocrinol Metab 1991;73:408-413

8. Padayatty SJ, Orme SM, Nelson M, Lamb JT, Belchetz PE. Bilateral sequential inferior petrosal sinus sampling with corticotrophin-releasing hormone stimulation in the diagnosis of Cushing's disease. Eur J Endocrinol 1998;139:161-166 